\title{
Pharmacovigilance and expedited drug approvals
}

\author{
Matthew Linger \\ Associate lecturer \\ School of Medicine \\ University of Queensland \\ Basic physician trainee \\ Royal Brisbane and \\ Women's Hospital

\section{Jennifer Martin} \\ Chair \\ Discipline of Clinical \\ Pharmacology \\ School of Medicine and \\ Public Health \\ University of Newcastle \\ Senior staff specialist \\ Hunter New England Health \\ Newcastle \\ New South Wales
}

\section{Keywords}

adverse effects, drug regulation, postmarket surveillance, Therapeutic Goods Administration

Aust Prescr 2018:41:50-3 https://doi.org/10.18773/ austprescr.2018.010

\section{SUMMARY}

Pharmacovigilance is the detection and assessment of adverse events related to any drug used in clinical practice.

In Australia adverse events can be reported to the Therapeutic Goods Administration. Reports are encouraged, even if the drug is old or the prescriber is only suspicious of an adverse event.

Australian information about adverse events can be found online in the Database of Adverse Event Notifications and in the publication Medicine Safety Update.

The Therapeutic Goods Administration is currently exploring expedited approval pathways to enable some drugs to reach the market quickly. As there will be limited clinical data about these drugs, postmarketing pharmacovigilance will be of increased importance.

\section{Introduction}

Pharmacovigilance is the science and activities relating to the detection, assessment, understanding and prevention of adverse effects or any other drugrelated problem. ' Most reporting of adverse effects occurs after a drug is marketed. Postmarketing pharmacovigilance is essential as adverse events often only become apparent after a drug enters clinical practice. Premarket clinical trials are limited by short duration and small sample sizes. The patients are tightly selected, with strict inclusion and exclusion criteria. This limits the power of the trials to detect adverse events that occur rarely, after a protracted period of time, or in patients who are different from the study population.

\section{Pharmacovigilance in Australia}

Pharmacovigilance formally began in Australia in 1963, as a response to reports of thalidomide embryopathy, with the formation of the Australian Drug Evaluation Committee. Despite multiple policy and committee name changes, data on adverse events have been collected constantly since then. As of January 2017, the Advisory Committee on Medicines, a subcommittee of the Therapeutic Goods Administration (TGA), is responsible for pre- and postmarketing surveillance, including pharmacovigilance.

In the past, adverse events were reported to the TGA by the submission of a 'blue card'. ${ }^{2}$ These cards are no longer available in a physical form. Clinicians can now notify the TGA of adverse events via the online Australian Adverse Drug Reactions Reporting
System. ${ }^{3}$ Alternatively reports can be made via telephone, post, fax and email. Anyone, including the general public (on a separate online consumer portal), can report adverse events to the TGA.

A report can be made even if there is only a suspicion of a drug causing an adverse effect. It is the TGA's responsibility to investigate and determine causality. Ideally, all adverse events should be reported, but the TGA is most interested in those events listed in Box 1. Reporting already known or common adverse events helps the TGA continue to build the 'safety profile' of a drug.

Reporting by clinicians and the general public is voluntary. In contrast, sponsors of both registered and listed drugs are legally mandated to report to the TGA all suspected adverse events they receive or become aware of from any source, even if the sponsor does not agree that there is causality. In 2015, the TGA received 17000 reports with 54\% coming from sponsors and $15 \%$ from state and territory health departments (reporting adverse

\section{Box 1 Adverse events of particular interest to the Therapeutic Goods Administration}

Adverse event related to newly listed or registered drugs Adverse event related to medicine or vaccine interactions Suspected adverse event not listed in product information or in medical resources

Adverse event leading to death, admission to hospital, prolonged hospitalisation or birth defects 
events following immunisations). Only $4 \%$ of the reports came from GPs. ${ }^{4}$ From a quality perspective, not all reports may be considered equal, with sponsor reports more likely to lack important causal and correlative data. ${ }^{5}$

All data reported to the TGA are entered into the Australian Adverse Drug Reactions Reporting System. Data are also submitted to VigiBase, the World Health Organization's international database of adverse drug events. These databases are analysed to detect signals which may identify previously unrecognised safety problems, an increased frequency or severity of adverse events, or patient groups that are particularly sensitive to adverse events.

Adverse event data reported to the TGA since 1971 are publically available through the online Database of Adverse Event Notifications, established in October 2012. It is important to be aware that this database does not contain all known adverse events and cannot be used to determine adverse event rates. Clinicians can also obtain information on emerging safety concerns and adverse events in the publication Medicines Safety Update ${ }^{6}$ or via TGA alerts.

VigiAccess is the online access point for international data submitted to VigiBase (vigiaccess.org).

Australian reporting has led to the early recognition of adverse events. Examples include the risk of liver failure from lumiracoxib, ${ }^{7}$ black cohosh ${ }^{8}$ and flucloxacillin, ${ }^{9}$ and acute kidney injury from the 'triple whammy' (combination of ACE inhibitor, nonsteroidal anti-inflammatory and diuretic). ${ }^{10}$ Recently, reporting identified the risk of QT prolongation with denosumab." The Table highlights other significant safety issues noted by the TGA since 2010 .

Further information on Adverse Event Reporting is freely available through the NPS MedicineWise module 'Safety through Adverse Event Reporting' at www.nps.org.au/cpd/activities/safety-throughadverse-event-reporting.

\section{Limitations}

There are significant limitations with Australian adverse event reporting. Like other methods of observational research, the lack of a known sample size limits the ability to determine the rate of events. The numerator is also highly dependent on reporting by clinicians and the general public. Voluntary reporting leads to significant underreporting of adverse events. In the UK it estimated that reports probably represent less than $10 \%$ of actual events. ${ }^{12}$ Furthermore, only basic demographics are collected by the TGA (Box 2). No comorbidity data are available. These factors limit the ability to determine contributory and confounding factors to an adverse event.

\section{Pharmacovigilance and expedited approvals}

A review of medicines and medical device regulation in 2015 has recommended that the TGA implement expedited pathways for promising new drugs. ${ }^{13}$ This would enable the TGA to grant provisional approval of a new drug on the basis of early data, if the immediate availability of the drug outweighs the risk that additional data are still required. Similar pathways currently operate in Europe, Canada and the USA. ${ }^{14}$

In response to the review, the TGA released two consultation papers in 2017. The first aimed to seek opinions on enhancements to the current Medicines Vigilance Framework in order to better identify and address medicine safety concerns. ${ }^{15}$ Specifically, the Black Triangle Scheme, similar to that already operating in Europe, will be introduced to identify newly available drugs requiring increased vigilance. This will alert clinicians and consumers that these drugs are subject to additional monitoring and prompt them to report adverse events to the TGA. This may improve the rate of reporting in the postmarketing phase to help identify rare adverse events. Changes are also being proposed for the product information to improve the accessibility of prescribing information. ${ }^{15}$

The second paper asked for discussion of a provisional approval pathway. ${ }^{16}$ This pathway is designed to permit the clinical use of 'promising' medicines for patients with unmet clinical needs earlier than would normally be allowed. Provisional approval would be granted with significantly less clinical data than currently required. Decisions are likely to be made before phase III trials have been designed. This is important as many clinical trials fail from lack of efficacy, safety concerns, or a combination. ${ }^{17}$ Other phase III trials may meet the primary end point, but find mortality is worse, as seen with evolocumab and fibrates. ${ }^{18,19}$

In order to obtain full registration, sponsors must submit confirmatory data on efficacy and safety. However, there is the real possibility that a promising drug is never given full approval because subsequent trials do not confirm a benefit. By then the drug may have been used in clinical practice for up to two years under provisional approval. Increased pharmacovigilance will therefore be essential for these new drugs.

\section{Safety concerns}

Bypassing the traditional premarket approval process moves the experimentation phase of drug development into the real world. Under provisional approval, drugs will be applied in clinical practice before their comparative safety and efficacy are known and without the stringent follow-up and protection afforded by clinical trials. While there will 


\section{Table Examples of adverse events reported to the Therapeutic Goods Administration}

\begin{tabular}{ll}
\hline Drug & Adverse event \\
\hline Sodium glucose co-transporter 2 inhibitors & Diabetic ketoacidosis (atypical presentation) \\
\hline Risperidone & Cerebrovascular events in patients with dementia \\
\hline Infliximab & Non-melanoma skin cancers (particular in psoriasis) \\
\hline Methotrexate & Hepatitis B reactivation \\
\hline Non-steroidal anti-inflammatory drugs (over-the-counter doses & Cardiovascular events \\
\hline used for prolonged periods) & Diclofenac - hepatotoxicity \\
\hline Combined oral contraceptives and hormonal replacement therapy & Potential link with inflammatory bowel disease \\
\hline Metoclopramide & Extrapyramidal events and cardiac conduction - \\
\hline Pregabalin & new recommendations for prevention \\
\hline Zolpidem & Suicidal ideation \\
\hline Duloxetine & Next day impairment \\
\hline Rotavirus vaccine & Serotonin syndrome \\
\hline Denosumab & Intussusception \\
\hline Proton pump inhibitors & Severe hypocalcemia \\
\hline Clozapine & Acute interstitial nephritis \\
\hline Exenatide & Constipation \\
\hline
\end{tabular}

be increased emphasis on pharmacovigilance in the provisional pathway, including random audits, these mechanisms have not yet been fully scrutinised and may not provide enough protection for patients.

Sponsors are legally mandated to report all negative outcomes they become aware of, but there is no imperative for them to actively search for adverse events. As reporting by clinicians will remain voluntary it is likely that there will be significant under-reporting of adverse reactions to provisionally approved drugs. However, adverse events from specialist-only drugs such as immunotherapies may have a higher rate of detection and reporting due to hospital reporting systems.

Postmarketing safety concerns have been raised with the provisional approval process implemented in Canada, a process similar to that proposed in Australia. There is a statistically significant risk that drugs approved under this mechanism will receive a serious safety warning or be removed from market compared to those approved by a standard review process. ${ }^{20}$

Despite these concerns we are still not entirely certain how the provisional approval pathway will be implemented in Australia by the TGA. At present, the TGA is yet to announce its complete plans for monitoring the safety and efficacy of these

\section{Box 2 Data collected by the Therapeutic Goods Administration}

Basic patient demographics (sex, date of birth or age, weight, ethnicity, state)

Drug details (dose, frequency, form, route, date started, date stopped, indication, batch number)

Adverse reaction (date of onset, description, severity, treatment, outcome, sequelae)

Reporter details (name and address)

Optional supporting documentation

provisionally approved drugs. The TGA already has the power to impose conditions on the registration of a new drug. For example, an existing condition of registration of new drugs has been the requirement for a risk management plan. ${ }^{21}$ The TGA will undertake monitoring to ensure the contents of these plans, such as collecting additional safety data, are carried out. ${ }^{15}$

\section{Future proposals}

The reason for the development of the TGA and its safety committees was to ensure safety and monitor new therapies in clinical practice. Patient protection is key if drugs are to be used in an experimental manner. In addition to the 
proposed pharmacovigilance measures in the provisional approval pathway, there could be a drug registry in order to prevent harm. This registry could be established and managed by pharmacoepidemiologists and linked research groups working with the TGA. Prescribers using provisionally approved drugs would be required to enter patient data on safety and outcomes into the register. Provisionally approved drugs could be identified in prescribing software, product information and in medicine resources through the TGA's Black Triangle Scheme. In this way serious adverse events and lack of efficacy would be identified early.

\section{Conclusion}

A balance between experimentation and the rapid provision of promising new drugs for serious or lifethreatening conditions is needed. Pharmacovigilance will be of increasing importance if drugs are approved for use on the basis of limited trial data. $<$

Jennifer Martin has contributed to the Therapeutic Goods Administration consultation processes as an employee of the University of Newcastle and as a member of the Australasian Society of Clinical and Experimental Pharmacologists and Toxicologists.

\section{REFERENCES}

1. World Health Organization. Essential medicines and health products. Pharmacovigilance. www.who.int/medicines/ areas/quality_safety/safety_efficacy/pharmvigi/en/ [cited 2018 Mar 1]

2. Mackay K. Showing the blue card: reporting adverse reactions. Aust Prescr 2005;28:140-2. https://doi.org/10.18773/ austprescr.2005.107

3. Therapeutic Goods Administration. Reporting problems. www.tga.gov.au/reporting-problems [cited 2018 Mar 1]

4. Therapeutic Goods Administration. Medicines and vaccines post-market vigilance - statistics for 2015. Version 1.0, Nov 2016. Canberra: Department of Health; 2016. www.tga.gov.au/ medicines-and-vaccines-post-market-vigilancestatistics-2015 [cited 2018 Mar 1]

5. Moore TJ, Furberg CD, Mattison DR, Cohen MR. Completeness of serious adverse drug event reports received by the US Food and Drug Administration in 2014. Pharmacoepidemiol Drug Saf 2016;25:713-8. https://doi.org/ 10.1002/pds.3979

6. Therapeutic Goods Administration. Medicines Safety Update 2010-present. Canberra: Australian Government Department of Health. www.tga.gov.au/publication/medicines-safetyupdate [cited 2018 Mar 1]

7. Therapeutic Goods Administration. Withdrawal of lumiracoxib in Australia. Australian Adverse Drug Reactions Bulletin 2008;27:6-7. www.tga.gov.au/publication-issue/ australian-adverse-drug-reactions-bulletin-vol-27-no-2 [cited 2018 Mar 1]

8. Therapeutic Goods Administration. Black cohosh and liver toxicity - an update. Australian Adverse Drug Reactions Bulletin 2007:26:11. www.tga.gov.au/publication-issue/ australian-adverse-drug-reactions-bulletin-vol-26-no-3 [cited 2018 Mar 1]

9. Therapeutic Goods Administration. A comparison of dicloxacillin with flucloxacillin. Australian Adverse Drug Reactions Bulletin 1999;18:7. www.tga.gov.au/publicationissue/australian-adverse-drug-reactions-bulletin-vol-18-no-2 [cited 2018 Mar 1]

10. Thomas MC. Diuretics, ACE inhibitors and NSAIDs--the triple whammy. Med J Aust 2000;172:184-5.

11. Therapeutic Goods Administration. Denosumab and QT prolongation. Medicines Safety Update 2016;7:2.

www.tga.gov.au/publication-issue/medicines-safety-updatevolume-7-number-4-august-2016\#a2 [cited 2018 Mar 1]
12. Hazell L, Shakir SA. Under-reporting of adverse drug reactions: a systematic review. Drug Saf 2006;29:385-96. https://doi.org/10.2165/00002018-200629050-00003

13. Sansom L, Delaat W, Jorvath J. Review of medicines and medical devices regulation. Discussion paper. Nov 2014 www.adia.org.au/documents/item/2736 [cited 2018 Mar 1]

14. Martin J, Shenfield G. The hazards of rapid approval of new drugs. Aust Prescr 2016;39:2-3. https://doi.org/10.18773/ austprescr.2016.005

15. Therapeutic Goods Administration. Consultation: strengthening monitoring of medicines in Australia. Enhanced medicines vigilance. Version 1.0, March 2017. Canberra: Australian Government Department of Health; 2017. www.tga.gov.au/consultation/consultationstrengthening-monitoring-medicines-australia [cited 2018 Mar 1]

16. Therapeutic Goods Administration. Consultation: provisional approval pathway for prescription medicines. Proposed registration process and post-market requirements. Version 1.0, March 2017. Canberra: Australian Government Department of Health; 2017. http://www.tga.gov.au/ consultation/consultation-provisional-approval-pathwayprescription-medicines [cited 2018 Mar 1]

17. Grignolo A, Pretorius S. Phase III trial failures: costly, but preventable. Appl Clin Trials 2016;25:36-42.

18. Sabatine MS, Giugliano RP, Keech AC, Honarpour N, Wiviott SD, Murphy SA, et al.; FOURIER Steering Committee and Investigators. Evolocumab and clinical outcomes in patients with cardiovascular disease. N Engl J Med 2017;376:1713-22. https://doi.org/10.1056/NEJMoa1615664

19. Studer M, Briel M, Leimenstoll B, Glass TR, Bucher HC. Effect of different antilipidemic agents and diets on mortality: a systematic review. Arch Intern Med 2005;165:725-30. https://doi.org/10.1001/archinte.165.7.725

20. Lexchin J. Post-market safety warnings for drugs approved in Canada under the Notice of Compliance with conditions policy. Br J Clin Pharmacol 2015;79:847-59. https://doi.org/ 10.1111/bcp.12552

21. Therapeutic Goods Administration. Risk management plans for medicines and biologicals. 12 December 2017. https://www.tga.gov.au/publication/risk-managementplans-medicines-and-biologicals [cited 2018 Mar 1] 